\title{
"O rio é como o sangue da gente": Mineração e ambiente nos campos do Alto Camaquã
}

\author{
“THE RIVER IS LIKE OUR BLOOD” MINING AND ENVIRONMENT IN THE FIELDS \\ OF ALTO CAMAQUA
}

\section{“EL RIO ES COMO LA SANGRE DE LA GENTE": MINERÍA Y MEDIO AMBIENTE EN LOS CAMPOS DEL ALTO CAMAQUÃ}

\author{
Vagner Barreto Rodrigues* \\ Daniel Vaz Lima* \\ Flávia Maria Silva Rieth*1 \\ vgnrbrrt@@gmail.com
}

Recibido: 26/2/2020 Aceptado: 18/7/2020

\begin{abstract}
Resumo
Este ensaio reflete etnograficamente sobre a mobilização em defesa do Rio Camaquã, na Serra do Sudeste, na pampa brasileira, a partir das questões colocadas ao longo do Inventário Nacional de Referências Culturais Lida Campeira (INRC Lida Campeira) e de trabalho de campo na parte alta da bacia, nos "campos de pedra" ou "campos dobrados". A região do Alto Camaquã, alvo da mineração desde o século 18, apresenta um paradoxo: de um lado é onde a biodiversidade do bioma pampa encontra-se mais preservada, de outro, figura como a mais empobrecida do estado. Em 2014, as empresas transnacionais Nexa Resources (ex-Votorantim Metais) e Iamgold Corporation solicitaram a abertura de um projeto de mineração de chumbo e outros metais pesados no distrito de Minas do Camaquã, com previsão de utilização da água do rio. Nesse sentido, este texto acompanha a lida campeira e os modos de vida dos habitantes do Alto Camaquã, mas, também, a experiência histórica da mineração - e o terror decorrente dela.
\end{abstract}

Palavras-chave: mineração, rio Camaquã, Inventário Nacional de Referências Culturais, Lida campeira, Pampa

\begin{abstract}
This abstract ethnographically reflects about the movilization in defense of the Camaqua River, in the Serra do Sudeste, in the Brazilian pampa, based on questions raised along the Lida Campeira - National Inventory of Cultural References (INRC Lida Campeira) and the field work in the high part of the basin, in the "stone fields" or "campos dobrados". The Alto Camaqua region, a mining target since the 18th century, presents a paradox: on one hand it is where the biodiversity of the pampa biome is preserved the most, on the other hand, it is considered as the poorest part of the state. In 2014, the transnational companies Nexa Resources (ex-Votorantim Metais) and Iamgold Corporation requested the opening of a mining Project of lead and other heavy metals in the district of Minas of Camaqua, with the expectation of using water from the river. In this sense, this text follows the lida campeira and the lifestyle of the inhabitants of Alto Camaqua, but also the historical mining experience - and resulting terror of it.
\end{abstract}

Keywords: Mining, Camaqua river, National Inventory of Cultural References, Lida campeira, Pampa

\footnotetext{
$1 *$ Universidade Federal de Pelotas
}

Tekoporá ${ }^{\circledR}$. Centro Universitario de la Región Este. Universidad de la República (C) Barreto, Vaz, Silva (2020)

Este es un artículo de Acceso Abierto distribuido bajo licencia Creative Commons (CC BY NC 4.0) 


\section{Resumen}

Este ensayo reflexiona etnográficamente sobre la movilización en defensa del Río Camaquã, en la Sierra del Sureste, pampa brasileña, a partir de las cuestiones planteadas a lo largo del Inventario Nacional de Referencias Culturales "Lida Campeira" (INRC Lida Campeira) y de lo trabajo de campo en la parte alta de la Cuenca, en los "campos de piedra" o "campos dobles". La región del Alto Camaquã, que ha sido objeto de la minería desde el siglo XVIII, presenta una paradoja: por un lado, es donde más se conserva la biodiversidad del bioma pampa, al mismo tiempo, figura como la más empobrecida del estado. En 2014, las empresas transnacionales Nexa Resources (antes Votorantim Metais) e Iamgold Corporation solicitaron la apertura de un proyecto minero de plomo y otros metales pesados en el distrito de Minas do Camaquã, con previsión de la utilización del agua del rio. En este sentido, este texto acompaña la "lida campeira" y las formas de vida de los habitantes del Alto Camaquã, pero también la experiencia histórica de la minería y el terror resultante de ella.

Palabras clave: minería, río Camaquã, Inventario Nacional de Referencias Culturales, Lida campeira, Pampa.

\section{Fantasmas}

Naquela escuridão fechada nenhum tapejara seria capaz de cruzar pelos trilhos do campo, nenhum flete crioulo teria faro nem ouvido nem vista para bater na querência; até nem sorro daria no seu próprio rastro! E a noite velha ia andando... ia andando... João Simões Lopes Neto, A Mboitatá.

Nosso caminho se situa contra a corrente, rio acima, próximo ao sopé dos Andes, onde os curandeiros índios estão atarefados, tratando os colonizadores dos fantasmas que os atacam. Michael Taussig, Xamanismo, colonialismo e o homem selvagem

Neste ensaio, buscamos refletir sobre a etnografia que compõe a pesquisa do Inventário Nacional de Referências Culturais - Lida Campeira na Região de Bagé/RS (INRC Lida Campeira) , a partir da extensão das pesquisas na Serra do Sudeste, na pampa brasileira, extremo sul do Rio Grande do Sul, onde, desde 2016, tem sido realizado trabalho de campo. O INRC é uma metodologia desenvolvida pelo Instituto do Patrimônio Histórico e Artístico Nacional (Iphan) para conhecimento de bens culturais imateriais representativos de determinado grupo. 0 Inventário tem como objetivos identificar, documentar e construir conhecimento sobre a lida campeira para fins de registro como Patrimônio Cultural Imaterial Brasileiro, categoria reconhecida a partir de 2006, após acordo ratificado com a UNESCO.

Por meio da Etnografia, a equipe vem acessando a área cultural do Sul - que, para Leal (2019), não coincide necessariamente com os limites políticos do estado do Rio Grande do Sul "ou mesmo os da nação Brasil" (p. 20). 0 trabalho de campo busca acompanhar os modos de vida dos detentores e das detentoras dos ofícios denominados campeiros, que vivenciam ou vivenciaram a lida campeira da pecuária extensiva, na região de Bagé e na região do Alto Camaquã (Rieth, Lima, Rodrigues e Herrmann, 2019). São proprietários de terras - de médias e grandes extensões, assim como propriedades familiares - e/ou peões campeiros, capatazes, trabalhadores e trabalhadoras rurais, que desempenham ou desempenharam as atividades de doma, de pastoreio (de ovinos, de bovinos, de equinos e de caprinos), de esquila, o ofício de guasqueiro, a tropeada, o artesanato em lã, a lida caseira, entre outros saberes e fazeres. 

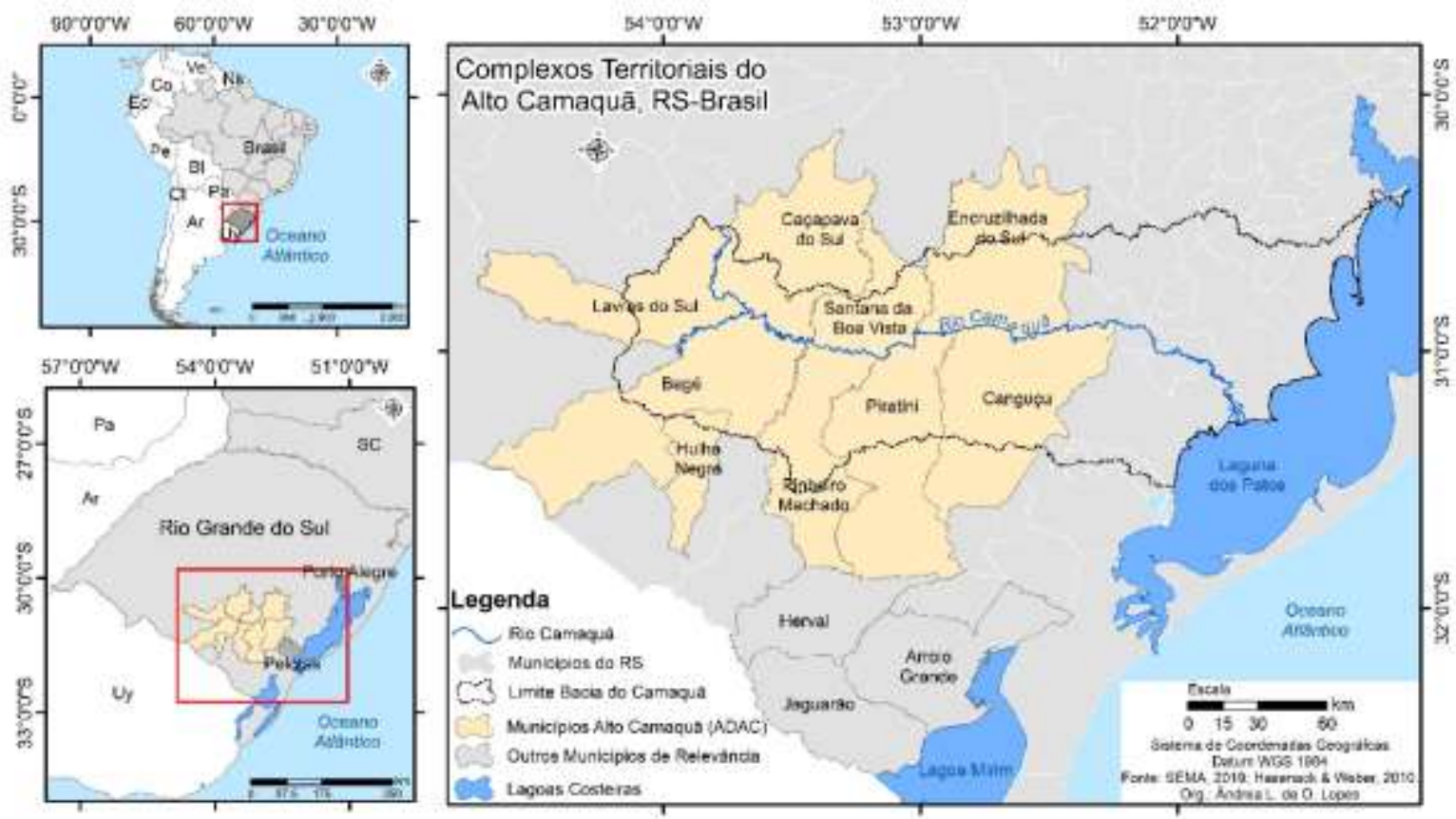

Imagem 1: Complexos territoriais do Alto Camaquã. (Fonte: SEMA - Acervo INRC Alto Camaquã. Org.: Andrea L. de O. Lopes)

A Bacia do Rio Camaquã reúne pecuaristas familiares, quilombolas e indígenas Guarani, entre outras populações tradicionais, que, historicamente, habitam os campos de pedra e os campos dobrados na pampa (Mazurana, Dias e Laureano, 2016; Rieth et al., 2013; Kosby, 2017). A partir da solicitação das comunidades, a equipe de pesquisadores passou a dialogar com coletivos que acompanham os projetos de megamineração no Rio Grande do Sul e na área do Inventário. Em 2014, as transnacionais Nexa Resources (ex-Votorantim Metais) e a companhia de mineração de ouro Iamgold Corporation protocolaram o Projeto Caçapava do Sul , uma iniciativa conjunta [joint venture] que pretende instalar três cavas a céu aberto para a extração de chumbo, de cobre, de zinco e de ouro e de prata, na parte alta da Bacia Hidrográfica, no Cerro dos Martins, 3ํ distrito de Caçapava do Sul, localidade de Minas do Camaquã, distante 70km do centro do município.

Minas do Camaquã, limitada pelo Rio Camaquã no sentido Sul-Sudeste (S-SE), faz divisa com os municípios de Bagé, Pinheiro Machado e Santana da Boa Vista. De acordo com Silva (2008), a área do Escudo Sul-rio-grandense apresenta relevo acidentado, de formações superficiais rasas e, frequentemente, com afloramentos de rocha. A localidade de Minas do Camaquã surgiu em função da instalação da Rio Grande Gold Mining Limited, em 1870. A iniciativa de extração de cobre partiu de ingleses que exploravam ouro nas proximidades, em Lavras do Sul. 0 minério era transportado em carreta puxada por bois até Hulha Negra, distante 90km, de onde seguia de trem até o Porto na cidade de Rio Grande e de navio para a Europa. Os ciclos de exploração, que seguiram, de forma descontinua, até o fim da década de 1990, deixaram um amontoado de ruínas da mineração, com área industrial, linhas de transporte, barragem de rejeitos, poluição do Camaquã. Ficou, também, o complexo de sete vilas operárias abandonadas, com algumas centenas de moradores - o que fez a comunidade ser tratada por 
parte da mídia como uma "cidade fantasma" .

Os estudos de impacto ambiental referentes à instalação do empreendimento, porém, não levaram em conta a configuração da Bacia do Rio Camaquã. As considerações de possíveis impactos ambientais realizados para a, então, Votorantim Metais consideraram o ambiente como uma área fixa, medida em metros quadrados, com alcance determinado pelos limites políticos e administrativos dos municípios de Caçapava do Sul e Santana da Boa Vista/RS, para mensurar os riscos. Nessa concepção, o Rio Camaquã é considerado uma "barreira física", que impediria impactos aos municípios de Bagé e Pinheiro Machado, localizados no outro lado do Rio (Eia-Rima Projeto Caçapava, 2016, p. 31).

0 Eia-Rima do Projeto vai de encontro às compreensões dos habitantes da região, marcada pela pecuária familiar extensiva e pela disseminação da presença negra, desde o século 18, conforme apontam os trabalhos de Saint-Hillaire (2002), Isabelle (2006), Corrêa (2012), Fernandes e Miguel (2016), Osório (2016). Os "campos dobrados" da região do Alto Camaquã apresentam topografia acidentada, afloramentos rochosos, cordilheiras e "guaritas", um mosaico de "campo sujo", campo com mato, pedra, rio (Rieth et al., 2019). Não por acaso, a Serra do Sudeste, serviu como local estratégico para diversos coletivos ao longo da formação sociocultural da região. Além de famílias de pecuaristas, habitam as margens do Rio Camaquã grupos indígenas e povos quilombolas, como o do Quilombo de Palmas, em Bagé, o do Quilombo Corredor dos Munhós, em Lavras do Sul e o do Quilombo Tio Dô, em Santana da Boa Vista, entre outros (Mazurana, Dias e Laureano, 2016). De acordo com Kosby (2017), os campos dobrados configuram uma possibilidade de "fuga para fora" (p. 48), para locais de difícil acesso, os fundões das propriedades, os peraus e penhascos nos rincões do inferno. Assim, conforme Ingold (2000), habitar o ambiente implica juntar-se aos outros entes que formam o mesmo.

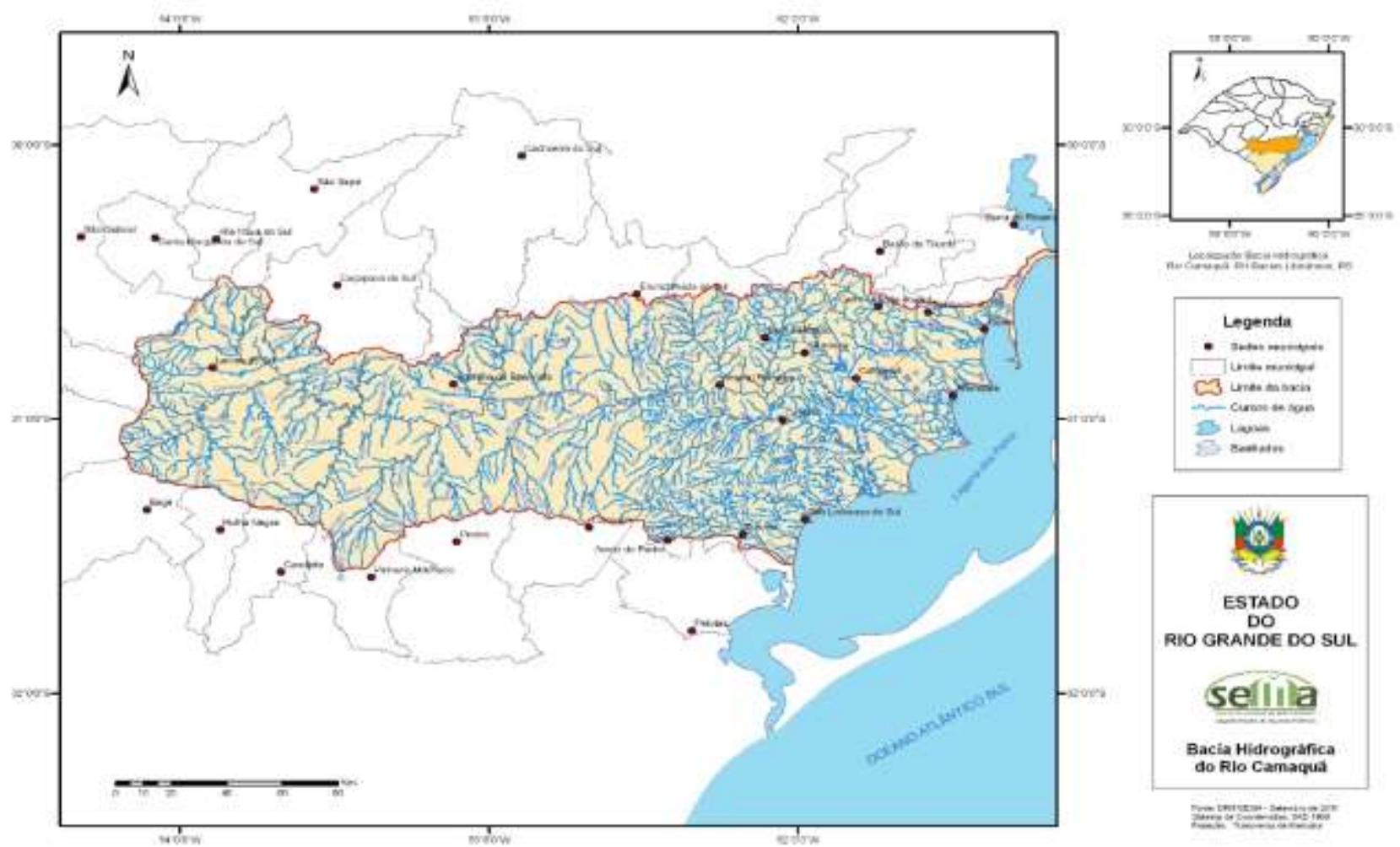

Imagem 2: Bacia Hidrográfica do Rio Camaquã (Fonte: Comitê de Gerenciamento da Bacia Hidrográfica do Rio Camaquã (2015) 
Para além de uma "barreira física", de acordo com aqueles que habitam o Alto Camaquã, o Rio é narrado como uma malha (Ingold, 2012), formada pelas múltiplas linhas que conectam aqueles que vivem com o rio, ao longo de mais de 400 quilômetros de extensão, através de 28 municípios. Isso pode ser minimamente representado por meio da Bacia Hidrográfica que dá forma ao Camaquã.

Nesse sentido, este ensaio reflete etnograficamente sobre a lida campeira e a mobilização em defesa do Rio Camaquã, por meio das pesquisas de patrimônio cultural imaterial realizadas sobre a pecuária extensiva na pampa brasileira, mas, também, da experiência da mineração e das histórias de terror decorrentes dela. No segundo tópico, pensamos historicamente a colonização na região de Minas do Camaquã, através do avanço de projetos de mineração na Serra do Sudeste, às voltas com ciclos de garimpo e de exploração, desde o século 18. No terceiro tópico, destacamos a etnografia da lida campeira na região do Alto Camaquã, por meio dos saberes e fazeres tradicionais da pecuária familiar extensiva em campo dobrado ou campo de pedra, e a manifestação dos impactos gerados por processos de mineração no modo de vida campeiro. Por fim, no quarto tópico, consideramos a intensificação dos conflitos socioambientais no Rio Grande do Sul e as apropriações do INRC Lida Campeira pelas comunidades.

\section{Túneis}

0 antropólogo Michael Taussig, tendo como pano de fundo processos históricos coloniais, volta-se para criação de sentidos em contextos de violência, como os canaviais, os seringais e as minas na Colômbia e na Bolívia, onde realizou trabalho de campo. Para Taussig (1993, p. 134):

"Aqui o Putumayo não passa de uma imagem, no estágio global de desenvolvimento do fetiche das mercadorias; pensem também no Congo, com sua borracha e seu marfim, na escravização dos Yaqui, nas lavouras de sisal no Yucatán, no México, no derramamento de sangue genocida na trágica Patagônia, tudo isto acontecendo quase ao mesmo tempo."

Em diálogo com Baretta e Markoff (1978), a expansão colonial na América Latina lançou mão tanto da mineração quanto a pecuária para ocupação de territórios nativos, o que gerou confrontos violentos e mediações políticas no avanço das fronteiras pecuárias. Durante os combates, os conhecimentos da mão de obra pastoril sobre o território e o manejo dos animais eram elementos importantes para a manutenção das tropas - e as ferramentas de trabalho eram, virtualmente, as armas.

Logo, é possível identificar traços daquilo que Baretta e Markoff (1978) apontam como uma "tradição de violência" (p. 587), ou, como defende Taussig (1993), com a criação de "espaços de morte" (p. 26) decorrentes dos encontros coloniais. Ainda, para a antropóloga Anne Salmond (2014), refletir sobre as relações que determinados grupos mantêm com as águas e fontes hídricas é uma boa forma para compreender o confronto de concepções nativas com outras lógicas sobre o território, bem como as implicações que tais noções geram para o acesso e domínio da natureza colonizada. Conforme a antropóloga, o Rio Whanganui, na Nova Zelândia, não é apenas a fonte de vida e bem estar para as populações Maori que vivem ao seu redor, mas um todo vivo, que conecta a montanha, as florestas, os afluentes, as enseadas e o mar com os 
povos tradicionais.

Voltamos à região do Alto Camaquã e a um aparente paradoxo: a região mais preservada do bioma pampa, com, aproximadamente, $80 \%$ de cobertura nativa, é considerada pelo Estado como a mais empobrecida do Rio Grande do Sul. Municípios como Santana da Boa Vista, Encruzilhada do Sul, Canguçu, Piratini ocupam os últimos lugares no ranking do Índice de Desenvolvimento Humano (IDH) do estado. Borba (2016) indica que o Alto Camaquã não teve "êxito na implementação dos modelos de desenvolvimento propostos" (p. 187). As particularidades da região, pouco indicada para a agricultura de grande porte, fazem com que cerca de $80 \%$ a $90 \%$ das propriedades sejam voltadas para a pecuária familiar, com pouca dependência em relação a insumos externos e autonomia em relação ao mercado.

A mineração ocupou espaço entre os projetos de desenvolvimento voltados para a região, em diferentes momentos históricos. 0 reconhecimento do potencial mineral é antigo e deixou registros na literatura dos viajantes, desde o início da ocupação do território. 0 francês Arsène Isabelle (2006 [1835]) que cruzou pelo Rio da Prata e pelo Rio Grande do Sul, destacou em seus diários a presença da mineração e do garimpo, assim como a utilização de mão de obra escravizada no trabalho (p. 187):

"[1ํo março 1834] A umas vintes léguas mais ao sul, perto da pequena vila de Caçapava, encontraram-se outras minas de ouro em exploração, e que dão menos trabalho. É um rio chamado Camaquã, um dos afluentes da lagoa dos Patos, que se encarrega de desprendê-las e transportá-las como as areias e cascalhos do seu leito. Uma infinidade de regatos e de terrenos são auríferos, nesta província, mas os métodos de lavagem são muito maus e o pó que se obtém não traz grandes lucros ao proprietário dos negros empregados nesse trabalho."

De acordo com Cabreira (2008), o coronel João Dias dos Santos Rosa, dono do que, atualmente, constitui grande parte de Minas do Camaquã, deu abertura à mineração de cobre na área, na década de 1860, após enviar algumas rochas coloridas para Dom Pedro II, durante a passagem do Imperador por Caçapava. Segundo Troian (2009) um primeiro ciclo de exploração ocorreu de 1870 a 1887, momento de formação da infraestrutura de acesso às minas pela empresa The Rio Grande Gold Mining Limited, na parte leste do cerro João Dias, na micro bacia do Arroio João Dias, na jazida de cobre chamada "galeria dos ingleses" (p. 18). Conforme Nogueira (2012), de 1888 a 1899, em um segundo ciclo, os comerciantes alemães Maximiliano Saenger, Ricardo Saenger e Emílio Kleinod, de Pelotas, dedicaram-se à extração manual de minério, que apresentava custos elevados devido ao transporte e exportação para a Inglaterra, em um cenário de queda dos preços internacionais do cobre, o que logrou a iniciativa.

A extração reiniciou em 1901, conforme Troian (2009) sob propriedade da Companhia Belga, a Societé Anonime des Mines de Cuivre de Camaquan, com sede em Bruxelas e filial brasileira, que abriu outra galeria, no flanco oeste, a chamada "galeria belga" (p. 19). Os belgas foram responsáveis pela construção de uma barragem no Arroio João Dias, para o fornecimento de água e de energia, e de uma usina de beneficiamento, onde era feito o processo de concentração dos metais. Segundo Von Ahn (2018), o descarte dos rejeitos era realizado na área de beneficiamento, "às margens do Arroio João Dias" (p. 66-67). As atividades, porém, encerraram em 1909, em função da expansão colonial na África e da descoberta de minas no Congo. Os invernos rigorosos, os períodos chuvosos, as estradas de terra em condições precárias, o transporte por carreta de boi, eram alguns dos fatores que encareciam o escoamento até o porto, na cidade de Rio Grande/RS.

No fim da década de 1920 até meados de 1930, o Serviço Geológico e Mineralógico realizou novas prospecções sobre o potencial mineral do Rio Grande do Sul, levantamento continuado pelo Serviço de Fomento da Produção Mineral. Para Nogueira (2012), as pesquisas 
motivaram a criação da Companhia Brasileira de Cobre (CBC), em 1942, uma iniciativa de capital misto, tendo como acionistas majoritários o governo do Rio Grande do Sul e o Grupo Pignatari, além do governo federal (p. 42). A CBC tinha como um dos objetivos diminuir a dependência nacional de importação de cobre e aproveitar o cenário de aumento do preço internacional, em função da $2^{\text {a }}$ Guerra Mundial.

A partir de 1957, o Grupo Pignatari assumiu o controle majoritário sobre as ações da CBC, por meio da Laminação Nacional de Metais. O Grupo era liderado pelo empresário e herdeiro ítalo-brasileiro Francisco Matarazzo Pignatari, de São Paulo, que manteve a exploração nas minas até 1974 quando a CBC retornou para o governo federal, via Banco Nacional de Desenvolvimento Econômico e Social (BNDES). De acordo com Nogueira (2012), o "tempo do Pignatari" (p. 131) costuma ser retratado como o período clássico da região. 0 empresário buscou construir uma comunidade modelo: no ponto mais elevado ficava sua residência oficial; nas partes altas e centrais ficavam as casas de diretores, gerentes, engenheiros e geólogos; os espaços intermediários eram ocupados por empregados técnicos e administrativos; e as periferias eram destinadas aos mineradores. Além dos salários serem melhores que os pagos na região, havia hospital, bloco cirúrgico, laboratório de exames, clube com sauna e piscina, escola, ginásio poliesportivo, time de futebol, presentes distribuídos às crianças em datas festivas, churrasco para toda a população e sessões no Cine Rodeio (cinema com fachada de madeira, no estilo de um saloon estadunidense).

De acordo com Troian (2009), a partir de 1976, foram encomendadas novas pesquisas geológicas, o que ocasionou a interrupção total dos trabalhos nas escavações (p. 20). Os estudos estimularam a preparação da infraestrutura e aquisição de maquinário para o novo plano da lavra e o andamento da extração. De acordo com Von Ahn (2018), o descarte dos rejeitos, que até então era feito às margens do Arroio João Dias, passou a ser realizado em uma barragem edificada em um meandro do curso do arroio, a jusante da vila das Minas do Camaquã. Porém, em 1981, quando as atividades do Projeto Expansão Camaquã (PEC) foram retomadas, o teor de cobre no minério lavrado ficou abaixo do esperado.

Em 1989, diante de endividamento, o BNDES privatizou a empresa, a partir da fundação da Bom Jardim S.A. por empregados da CBC. A privatização deu continuidade à mineração, realizada parcialmente a céu aberto, até 1996, quando as minas foram desativadas. 0 esvaziamento do distrito de Minas do Camaquã, que chegou a contar com cinco mil habitantes, aconteceu rapidamente nas décadas seguintes, mediante abandono ou venda das propriedades (Cabreira, 2008, Silva, 2008, Nogueira, 2012). Ficaram, ainda, algumas centenas de pessoas, que passaram a conviver com a falta de propostas econômicas e com a dificuldade de acesso a serviços básicos, como saúde e educação.

Ao todo, restaram $43 \mathrm{~km}$ de túneis, alguns inundados, com mais de 150 metros de profundidade. Uma das minas a céu aberto da CBC - que servia para atividades turísticas e de lazer - foi interditada pela Fundação Estadual de Proteção Ambiental Henrique Luiz Roessler (Fepam-RS), em 2017, e, em 2019, a barragem de rejeitos foi interditada pela Agência Nacional de Mineração (ANM), por não apresentar Declaração de Condição de Estabilidade (DCE).

\section{Lidas}

O Quilombo Corredor dos Munhós, em Lavras do Sul, encontra-se às margens do Arroio Camaquã-Chico, na localidade da Mantiqueira, em terras herdadas da antiga fazenda de Zeferino Munhós de Camargo. Para chegar até o quilombo, distante cerca de $15 \mathrm{~km}$ do centro do município, é preciso pegar a estrada para Bagé e entrar no Corredor da Mantiqueira. Após 
cruzar uma ponte, deve-se passar a primeira fazenda, à esquerda, e entrar na porteira, à esquerda. Deve-se, então, continuar pela estrada de campo, até encontrar um passo , onde é possível atravessar o Arroio. Após o passo, a primeira porteira leva até a comunidade. (Diário de campo, primavera de 2017).

De acordo com o quilombola Amilton Camargo, a comunidade mantém rebanhos ovinos, bovinos e alguns cavalos crioulos, "para os guris brincarem". Os rebanhos são criados coletivamente, em pasto nativo, nas terras do quilombo. Os moradores e moradoras costumam ter roçados para o consumo familiar, com milho, feijão, abóboras, e dispõem de frutas da estação, em quintas ao redor das casas e nos matos. Em alguns casos, recebem encomendas de peças artesanais em lã e trabalham nas fazendas (cabanhas) de criação de gado ao redor, como domadores, peões campeiros, cozinheiras, capatazes, aramadores - de forma ocasional, por temporada ou fixando-se em uma propriedade por períodos prolongados. (Diário de campo, primavera de 2017). Atualmente, mesmo rodeada por recursos hídricos, a comunidade do Quilombo Corredor dos Munhós enfrenta dificuldades no acesso à água doce, pois algumas nascentes de fora da comunidade podem estar contaminadas.

É em Lavras do Sul que a empresa Águia Metais pretende iniciar o Projeto Fosfato Três Estradas, para mineração de fosfato, na cabeceira do Rio Santa Maria, a $10 \mathrm{~km}$ de nascentes do Rio Camaquã. Segundo a empresa, o Projeto pretende extrair, beneficiar e comercializar fosfato para produção de matéria prima para a indústria de fertilizantes e de "corretivo agrícola". 0 tempo de vida útil da mina será de, aproximadamente, 15 anos, com possibilidade de ampliação para 20 anos. A mineração será realizada com cavas a céu aberto, barragem de rejeitos e captação de água de arroios ao longo do processo.

A sequência de projetos tem apontado o Rio Grande do Sul, especialmente "a metade sul" do Estado, como a nova fronteira da megamineração. Existem, atualmente, 5.192 requerimentos de autorização de pesquisa mineral encaminhados ao Departamento Nacional de Produção Mineral (DNPM), voltados para o subsolo gaúcho. E 166 projetos de mineração superaram a fase inicial. Quatro estão em estágio avançado: Mina Guaíba, em Charqueadas e Eldorado do Sul, para mineração de carvão, Projeto Retiro, em São José do Norte, para extração de titânio, Fosfato Três Estradas, em Lavras do Sul, para exploração de fosfato, e o Projeto Caçapava, em Caçapava, para mineração de chumbo, cobre e outros minerais. Cabe destacar que, desde o anúncio, os projetos geram fissuras, disputas e rompimentos nas comunidades; desestruturam redes sociais, rompem laços de reciprocidade, "dividem cidades", mediante posicionamentos favoráveis, contrários e "em cima do muro" (Diário de campo, inverno de 2019).

Em 2015, ao serem confrontados com a possibilidade de mineração de chumbo, a partir das notícias de jornais, os moradores de Palmas, em Bagé, buscaram acionar o Ministério Público, Universidades, políticos, movimentos sociais, solicitando mais informações e esclarecimentos por parte da Fepam-RS e das empresas mineradoras, uma vez que, além de poder comprometer a cadeia pecuária, a atividade impacta uma área considerada prioritária para conservação, segundo Ministério do Meio Ambiente. O Projeto Caçapava do Sul prevê a produção de 36 mil toneladas de chumbo, 16 mil toneladas de zinco e cinco mil toneladas de cobre - e, ainda, ouro e prata, anualmente. Otomar Vivian, prefeito de Caçapava do Sul, em 2016, durante a realização de Audiência Pública, convocada pelo Ministério Público, em Bagé, defendeu o projeto como "estratégico para o Rio Grande do Sul" (Diário de campo, verão de 2016).

Levar em consideração as características ambientais e socioculturais, entretanto, amplia a noção (re)produzida pelo Estado - e por certos campos da Ciência - sobre uma região historicamente narrada como pobre, bem como pouco habitada, tendo em vista a presença das 
populações tradicionais na pampa. No Distrito de Palmas, interior de Bagé, a família da pecuarista Márcia Colares mantém uma tradição que passa de geração em geração, que remete aos "tempos das sesmarias", como relatou. A cada Ano Novo, eles acampam na beira do Rio Camaquã. Dessa forma, o pai da pecuarista costumava "batizar os filhos" nas águas do Rio. "Uma das minhas irmãs nasceu em setembro. A gente brincava que ela tinha sido batizada primeiro, com três meses. Eu nasci em agosto, então foi com quatro meses". (Diário de Campo, verão de 2017).

Para Márcia, "o Rio é como o sangue da gente", fonte da vida que conecta humanos e aquilo que é vivo. A pecuarista recorda o desastre ambiental nos anos 1980, quando uma antiga barragem rompeu e ocasionou o vazamento de água contaminada com mercúrio, utilizado na mineração de ouro e de cobre. Naquela época, as águas do rio ficaram vermelhas. Era uma água estranha aos moradores. Logo, os peixes começaram a morrer e cobrir o Rio. Márcia lembra do cheiro de podre dos peixes em decomposição e do medo que os pais sentiram de entrar no Camaquã e de dar água aos rebanhos. "Foi ali na divisa, na virada do ano. Teve um transbordamento de produtos químicos no Rio, que deixou a água toda vermelha. E matou toda a vida do rio, naquela época. Eu lembro, assim, da tristeza profunda do meu pai, que já é falecido agora, e dos meus tios todos." (Diário de campo, primavera de 2017).

Segundo os interlocutores, o desastre de 1984 teve impacto direto na lida campeira, saberes e fazeres decorrentes da pecuária extensiva na pampa brasileira. Mais do que manejos, estes saberes e fazeres constituem modos de viver (Sennett, 2013), em que as habilidades incorporadas a partir do envolvimento perceptivo dos corpos com as materialidades, os bichos e os ambientes constituem diferentes formas criativas de conviver. Tornar-se campeiro envolve conhecer os animais, pois humanos, cavalos e cães estabelecem uma relação de ensino e aprendizagem na lida com os rebanhos. Práticas como acordar antes do raiar do sol, derrubar novilho com o corpo, conviver com animais predadores, enfrentar condições climáticas rigorosas, exigem de campeiros e campeiras uma aprendizagem atencional (Ingold, 2010), saber o que fazer, diante de situações diversas e, muitas vezes, imprevisíveis, em que estão em risco a vida de humanos e de outros animais. Experiências em que os viventes são domesticados no mesmo processo de criação dos animais e de campos. A lida campeira acompanha a especificidade do rebanhos, a particularidade dos animais, os ciclos de vida e de morte do gado, os horários do sol, os períodos de chuva e de estiagem, a relação predatória entre os bichos, como descrevem as pesquisas de Silva (2014), Lima (2015), Barreto (2015), Kosby (2017), e Rieth (2018).

Relações colocadas em risco perante a possibilidade de ciclos de mineração de chumbo e outros metais pesados na pampa. Os moradores relatam que por muito tempo o Camaquã, que era farto de grumatãs, dourados, piavas, pintados, jundiás, ficou sem peixes. Um rio sem peixes, sem vida. "0 mundo oficial se empenha em criar uma realidade mágica” (Taussig, 1993, p. 26). De acordo com a pecuarista Vera Colares: "Um modo de vida que hoje encontra-se sob forte ameaça pela presença de projetos minerários poluentes, com grande impacto na paisagem, nos recursos hídricos, como o Rio Camaquã. Um desses projetos, apresentados pela empresa Votorantim Metais/Nexa Resources, pretende explorar chumbo, cobre e zinco, em cavas às margens do Rio. Ameaça, assim, suprimir muitas de suas nascentes, bem como retirar um grande volume diário de água. Tais ações têm impactos sobre as comunidades, como a de Palmas, com metais pesados, tóxicos, colocando em risco de extinção 300 anos de história e de saberes que permitem a sustentabilidade de uma região." (Diário de campo, primavera de 2018).

É na região de Palmas que ocorre a "cria", reprodução dos rebanhos bovinos, que, ao 
completarem um ano, podem ser comercializados para outras localidades, onde seguem o ciclo de vida e de morte, no período de "engorda" dos animais (Diário de campo, primavera de 2017). As propriedades familiares costumam integrar ovinos, caprinos, equinos e bovinos, criados de forma extensiva, alimentando-se das pastagens naturais e da biodiversidade de espécies forrageiras, arbustos e árvores. São pitangueiras, cravos-do-mato, caraguatás, habenárias, tunas (cactos), guanxumas, juncos, figueiras, trevos, jerivás, petúnias. Algumas espécies são endêmicas da região e encontram-se sob ameaça de extinção. Os campos dobrados são conhecidos, também, como "campos sujos". Os campos são "sujos", exatamente, pela composição, um mosaico de campos, matos, pedras, rio, casas, quintas (pomares). (Rieth, 2018, Rieth et al., 2019).

Para Vera Colares: "A lida com os animais de produção, bovinos, ovinos e caprinos, envolve muitos ofícios, como a tropeada, quando os animais são levados de um lugar para outro por tropeiros a cavalo, acompanhados por cães. A principal habilidade para a lida em campos com muita vegetação arbórea, como no Alto Camaquã, é conhecer os animais. Os cães e o cavalo são parceiros inseparáveis nessas atividades. A doma, o aramado, a esquila costumam ser desempenhadas pelos membros da família, ou por vizinhos, no caso da pecuária familiar." (Diário de campo, primavera de 2018).

Muitas vezes, ouvimos que "sem cachorro é impossível camperiar nas Palmas". Para Régis Colares, "sem o cachorro tu não trabalha". De acordo com Eric Barreto (2019), os cães foram essenciais para a inserção da ovinocultura na região da Bacia do Rio da Plata e no Rio Grande do Sul. Fazem parte das atividades da lida campeira na retirada de algum animal desgarrado no mato, em locais inacessíveis a humanos e cavalos, na condução dos animais para contagem e abate, além de auxiliarem no transporte de tropas e na proteção contra ataques de predadores. Seu Leomar Alves, pecuarista familiar e morador no Quilombo de Palmas, treinava cães para a lida. Em depoimento à equipe do INRC Lida Campeira, em 2013, contou que ao trabalhar em uma estância na região de Bagé juntava um rebanho de 200 reses com três cachorros.

Os cuidados com os rebanhos devem ser redobrados na primavera, estação em que as temperaturas ficam mais amenas, época de parição, de nascimento dos bezerros e dos "cordeirinhos". Vacas, ao terem cria, se escondem nos matos e peraus, não atendem aos chamados, precisam ser procuradas. Os pecuaristas familiares costumam, nessa estação, reunir os aninais com mais frequência, para realizar contagem, ver andamento das gestações, ajudar algum parto e trazer cordeiros recém nascidos para próximo às casas, algo que, além de proteção, inicia a aproximação de filhotes e humanos. Combinações que levam em conta a relação de humanos, outros animais e ambiente (Ingold, 2000).

Ao acompanhar a lida campeira, os interlocutores evidenciam o conhecimento sobre a convivência histórica com os efeitos da mineração e as implicações de tentar barrar os fluxos das águas, de trata-la como barreira física. Apenas recentemente, os moradores do Alto Camaquã começaram a perceber o retorno dos peixes ao Rio, porém, não com a abundância de antes. Conforme seu Beto, peão campeiro e pecuarista familiar em Palmas, o desastre decorrente da mineração de cobre

"terminou matando todos os peixes, que até nem dourado existia aqui pra nós. Agora, tem. Agora não sei se vai ter mais adiante com o negócio dessa mina aí, que tá... tá pra sair. Mas tomara que não saia, isso aí é uma barbaridade que tão fazendo com o pessoal. Desde a fruta, a gente não vai poder comer a fruta, porque vai ficar envenenada da poeira que vem". (Diário de campo, primavera de 2017).

Para a pecuarista Vera Colares, mais uma vez, a vida no Alto Camaquã corre perigo: 
“As ameaças... são todas, assim, me parece. Na verdade, ele [o Projeto Caçapava] vai suprimir nascentes do Rio Camaquã, então, a quantidade de água vai reduzir, né. Ele vai retirar água, diariamente, do Camaquã. Assim, a gente olhando o Camaquã, agora, parece que é um grande rio, mas no verão, a gente passa no Camaquã com água pelo tornozelo, né, porque ele fica bem baixinho. Fica uma 'sanga', como a gente chama por aqui, né. Vai estragar o Camaquã, que o Camaquã pra nós é... é tudo, assim. Ele é fonte de lazer, porque a gente pesca aqui, é fonte de alimento, porque a gente toma banho, a gente pesca, e é fonte, também, de alimento, de água para nossos animais e pras próprias famílias. Fora o Rio Camaquã, a poeira que vai sair da mina, contaminada, ela vai vir pelos ventos para cima da nossa comunidade, então, vai contaminar nosso pasto, vai contaminar nossos animais. Vai contaminar a gente. Então, por qualquer lado que se possa olhar, é uma ameaça gravíssima pra nós. A gente acha... que a gente não vai sobreviver a essa mineração." (Diário de campo, primavera de 2017).

\section{Taperas}

Na Audiência Pública realizada em Bagé como parte das demandas da comunidade, em 2016, ao questionarmos o engenheiro responsável pelo empreendimento sobre as consequências que a mineração representa para as populações do Alto Camaquã e para a lida campeira, ouvimos como resposta que isso será levado em conta apenas no caso da atividade ser reconhecida como Patrimônio Cultural Imaterial brasileiro, observando o sítio do empreendimento (Diário de campo, verão de 2016).

Não deixa de chamar atenção que, no passado recente, a partir das décadas de 1980 e 1990, outro braço das empresas - a Votorantim Celulose - esteve entre as responsáveis pelo processo de implantação das lavouras de eucaliptos e de pinus por essa mesma região da pampa. Naquele momento, a produção de celulose para exportação era anunciada como a oportunidade de desenvolvimento para a "metade sul" do estado e batizada de "reflorestamento". A aquisição de parte dessas lavouras jamais foi realizada pelas empresas. Pecuaristas familiares que apostaram na ideia sentem-se lesados até hoje. Segundo os moradores, teve famílias que venderam os campos para as empresas, fecharam as casas e foram embora para a cidade. E existem relatos de olhos d'água e nascentes e sangas que desapareceram, em função do consumo d'água pelas lavouras, deixando taperas e pelo campo.

Em agosto de 2019, Artur Lemos, secretário estadual de Meio Ambiente e Infraestrutura, defendeu publicamente o chamado auto licenciamento ambiental, a partir da revisão do Código Estadual de Meio Ambiente. Para o secretário, em entrevista, o "empreendedor preenche o questionário (na internet), arquiva as exigências, tem um responsável técnico e a licença sai automaticamente." Para movimento sociais, entretanto, tratam-se de novas flexibilizações da legislação ambiental, que aumentam a exigência do fortalecimento dos órgãos fiscalizadores, em um momento de fragilidade do estado do Rio Grande do Sul. A presidente da Fepam-RS Marjorie Kauffmann, na mesma entrevista, admitiu que "muitas vezes, a estrutura criada de três licenças e documentações faz com que o empreendedor instale o empreendimento sem a nossa orientação." Entre os itens reavaliados pela nova legislação, está a silvicultura, que terá o processo de implantação facilitado.

Conforme Rieth et al. (2019), tendo em vista a pecuária familiar nos campos dobrados, a Embrapa Pecuária Sul/Bagé elaborou um projeto de desenvolvimento territorial endógeno, com centralidade aos modos de vida e nas relações dos habitantes com o ambiente, em que, para Borba (2016), "aos atores locais lhes sejam facultados o direito de gerar referências próprias” para definir as estratégias de mudança (p. 204). O projeto da Embrapa é 
desenvolvido, desde 2010, por meio da ADAC, a partir da articulação entre pecuaristas familiares e parceiros, como universidades, Embrapa, Emater, entre outros. A ADAC é uma rede de associações comunitárias, localizadas nos municípios que integram o projeto. Envolve um número aproximado de 500 famílias, distribuídas em 25 associações. Segundo Borba (2016), o objetivo é "apoiar e promover a preservação do patrimônio histórico, do meio ambiente, das culturas étnicas e produtivas do Alto Camaquã" (p. 207).

Para muitos interlocutores, o modo de vida campeiro é incompatível com a mineração de chumbo, fosfato e outros metais, o que configura a ruína da região. A investida da mineração, ao mesmo tempo, fez com que novos arranjos surgissem, por meio de associações criativas em campo, devido ao reconhecimento do Rio Camaquã enquanto conexão de vida, fundamental para toda a região. Um ente que envolve a vida, a experiência da mineração e a "cultura do terror", diante da possibilidade de destruição da biodiversidade e da contaminação das águas do Camaquã para a mineração, novamente.

Nesse sentido, a partir da interlocução da pesquisa do INRC Lida Campeira, buscamos refletir sobre uma pampa diversa, com disseminação de populações tradicionais, invisibilizadas ao longo de processos históricos de ocupação do território, que compartilham um ambiente que é fonte da vida. Ao reconhecerem os riscos de contaminação da mineração de chumbo e outros metais pesados, os interlocutores associam águas, animais, ventos, pedras, pois esses elementos fazem parte do modo de vida campeiro, com as implicações que os campos dobrados impõem na lida. 0 conhecimento sobre a região, por meio do manejo dos rebanhos, associa entes distintos, que compõem os caminhos da criação de humanos e de outros animais.

A consideração da Bacia, que conecta o Rio Camaquã com a Laguna dos Patos e, consequentemente, com o Oceano Atlântico, traz elementos importantes para refletir sobre a ocupação do ambiente, a partir do reconhecimento da lida campeira e dos saberes e fazeres dos povos tradicionais na pampa brasileira.

\section{Referências}

Baretta, S. e Markoff, J. (1978). Civilization and Barbarism: cattle frontiers in Latin America. Comparative Studies in Society and History, 20(4), pp. 587-620.

Barreto, E. "Por dez vacas com cria eu não troco meu cachorro": as relações entre humanos e cães nas atividades pastoris do pampa brasileiro. (2015). Dissertação (Mestrado em Antropologia) Universidade Federal de Pelotas, Pelotas.

Barreto, E. (2019). A gente sempre acredita nos nossos cachorros. Tessituras, 7(1) pp. 69-92.

Borba, M. F. (2016). Desenvolvimento territorial endógeno: o caso do Alto

Camaquã. In Waquil, P.D., Neske, M.Z. e Borba, M.F. (Orgs.), Pecuária familiar no Rio Grande do Sul: história, diversidade social e dinâmicas de desenvolvimento (pp 187-214). Porto Alegre: Editora da UFRGS.

Cabreira, D. P. (2008). O desenvolvimento insustentável no caso Minas do

Camaquã, Caçapava do Sul/RS. Dissertação (Mestrado em Extensão Rural). Universidade Federal de Santa Maria, Santa Maria. 
Corrêa, A. N. (2012). Roceiros, campeiros e domadores: o ofício do trabalho escravo na Vila de Caçapava (1831-1839). Revista Latino-Americana de História, 1, (3), pp. 58-73.

EIA-RIMA PROJETO CAÇAPAVA. (2016). Estudo de Impacto Ambiental. Relatório de Impacto Ambiental. Projeto Caçapava do Sul. Porto Alegre: Votorantim Metais.

Fernandes, V. e Miguel, L. A. (2016). Presença histórica da pecuária familiar na região da campanha do Rio Grande do Sul (Santana do Livramento, século XIX). In Waquil, P. D., Neske, M.Z. e Borba, M.F.(Orgs.). Pecuária familiar no Rio Grande do Sul: história, diversidade social e dinâmicas de desenvolvimento (pp. 41-64). Porto Alegre: Editora da UFRGS.

Ingold, T. (2000). The perception of the environment: essays on livelihood, dwelling and skill. London, UK: Routledge.

Ingold, T. (2010). Da transmissão de representações à educação da atenção. Educação, 1(33), pp. 6-25.

Ingold, T. (2012). Trazendo as coisas de volta à vida: emaranhados criativos num mundo de materiais. Horizontes Antropológicos, ano 18, 37, pp. 25-44.

Isabelle, A. (2006). Viagem ao Rio da Prata e ao Rio Grande do Sul. Brasília, Brasil: Editora do Senado.

Kosby, M. F. (2017). Alma-caroço: peregrinações com cabras negras pelo extremo sul do Brasil. Tese (Doutorado em Antropologia Social). Universidade Federal do Rio Grande do Sul, Porto Alegre.

Leal, O. (2019). Os gaúchos: cultura e identidade masculina no pampa. Tessituras, 7(1), pp. 1647.

Lima, D. V. (2015). "Cada doma é um livro": a relação entre humanos e cavalos no pampa sulrio-grandense. Dissertação (Mestrado em Antropologia). Universidade Federal de Pelotas, Pelotas.

Mazurana, J., Dias, J. e Laureano, L. (Orgs.). (2016). Povos e comunidades tradicionais do pampa. Porto Alegre, Brasil: Fundação Luterana de Diaconia.

Nogueira, J. (2012). Mineiros e engenheiros: memória, identidade e trabalho nas minas do Camaquã entre 1970 e 1996. Dissertação (Mestrado em História). Universidade Federal de Santa Maria, Santa Maria. 
Osório, H. (2016). Pastores, lavradores do Rio Grande, séculos XVIII e XIX. In Waquil, P. D., Neske, M.Z. e Borba, M.F. Pecuária familiar no Rio Grande do Sul: história, diversidade social e dinâmicas de desenvolvimento (pp. 15-40). Porto Alegre: Editora da UFRGS.

Rieth, F. (2018). Traçados. Áltera, 1(6), pp. 192-203.

Rieth, F., Kosby, M.F., Silva, L. Bilhalva, Rodrigues, M. Bonow, Dobke, P. e Lima, D. Vaz. (2013). Inventário Nacional de Referências Culturais: Lida Campeira na Região de Bagé/RS. V. 2. Arroio Grande: Complexo Criativo Flor de Tuna.

Rieth, F., Lima, D. Vaz., Rodrigues, V. B. e Hermann, M. (2019). “Aqui na lida é eu, a esposa e os cachorros": trabalho familiar e saberes pecuários nos campos dobrados do Alto Camaquã. Tessituras, 7(1), pp. 48-68.

Saint-Hillaire, A. (2002). Viagem ao Rio Grande do Sul. Brasília: Senado Federal.

Salmond, A. (2014). Tears of Rangi: water, power, and people in New Zealand. Hau, 4(3), pp. 285-309.

Schlee, A. G. (2019). Dicionário da Cultura Pampeana Sul-Rio-Grandense. Pelotas: Fructos do Paiz.

Sennet, R. (2013). 0 artífice. Rio de Janeiro: Record.

Silva, R. M. (2008). Espaço e tempo nas Minas do Camaquã em Caçapava do Sul/RS. Dissertação (Mestrado em Geociências). Universidade Federal de Santa Maria, Santa Maria.

Silva, L. Entre lidas: Um estudo de masculinidades e trabalho campeiro na cidade. (2014). Dissertação (Mestrado em Antropologia). Universidade Federal de Pelotas, Pelotas.

Simões Lopes Neto, J. (2011). Os contos e lendas. Pelotas: Fructos do Paiz.

Taussig, M. (1993). Xamanismo, colonialismo e o homem selvagem: um estudo sobre o terror e a cura. São Paulo, Brasil: Paz e Terra.

Troian, G. C. (2009). A cloritização na Mina Uruguai, Minas do Camaquã/RS-Brasil. Dissertação (Mestrado em Geociências). Universidade Federal do Rio Grande do Sul, Porto Alegre.

Von Ahn, M. M. (2018). Análise Antropogeomorfológica em Geossítio da história da mineração: estudo nas Minas do Camaquã - RS. Dissertação (Mestrado em Geografia). Universidade Federal de Pelotas, Pelotas. 